\title{
A Study on Disposal of Unidentified Dead Bodies in a Tertiary Care Hospital in Sri Lanka Along with Legal Provisions and Procedural Circumstances
}

\author{
Ariyarathna HTDW* \\ Department of Forensic Medicine, Faculty of Medical Sciences, University of Sri Jayewardenepura, Gangodawila, \\ Nugegoda, Sri Lanka.
}

\begin{abstract}
Introduction: It is mandatory for Forensic Pathologists (FPs)/Judicial Medical Officers (JMOs) in Sri Lanka to handle the disposal procedure of unidentified dead bodies, and it is not unusual for these doctors to face many hardships during this process. It requires the help of many stakeholders to fulfil all legal requirements before the proper disposal process. This retrospective data analysis was performed to study the demography of such decedents and also to address evidentially the prevailing issues surrounding the disposal of unidentified decedents. Based on the study the deficiencies and strengths of the present procedure of disposal of decedents were studied. The existing legal procedure of inquest in relation to the unidentified decedents was also studied.
\end{abstract}

Methodology: The details of the unidentified decedents available in the registers of the Colombo South Teaching Hospital were perused and analysed from August 2016 to August 2020. The communication file with police and the records pertaining to the mortuary coolers were also perused. The present law of the country related to the disposal of unidentified decedents and prevailing procedural circumstances are also scrutinized.

Results: One-hundred and forty-one (141) unidentified dead bodies were autopsied ( $03 \%$ of all dead bodies) during the four years. The male to female ratio was $13: 1$, and the majority of victims ( $\mathrm{n}=81$ and $57 \%$ ) were of $61-80$ years age range. The cause of death was natural in $81 \%$. After receiving the dead body, the meantime to perform the autopsy was 90 days and 5 days to dispose of the dead body. The Police had handed over $50 \%(\mathrm{n}=71)$ of decedents to the hospital.

Conclusion: The duration to perform the post-mortem examination from the date of handover was lengthy, and it revealed that this delay was due to the slow progression of essential initial steps that to be followed by the police. One recommendation to rectify this delay is utilizing the hospital web page to display details of the unidentified decedents. There is no "specified" procedure for the disposal of unidentified decedents in Sri Lanka. But it is covered under the inquest procedure and with the Departmental Orders of the Department of Police for a certain extent.

Keywords: Cause of death, disposal of the dead, inquest, unidentified dead bodies, unidentified decedents

Received: 10 May 2021, Revised version accepted: 24 June 2021, Published: 30 June 2021. *Corresponding author: Ariyarathna HTDW, $\triangle$ email: ariyaratna@sjp.ac.lk D ORCID: https://orcid.org/0000-0002-4266-5508

Cite this article as: Ariyarathna HTDW. A Study on Disposal of Unidentified Dead Bodies in a Tertiary Care Hospital in Sri Lanka Along with Legal Provisions and Procedural Circumstances. Medico-Legal journal of Sri Lanka. 2021;9(1):1-6.

DOI: http://doi.org/10.4038/mljsl.v9i1.7436

Copyright: @ 2019 with the Medico-legal Journal of Sri Lanka.

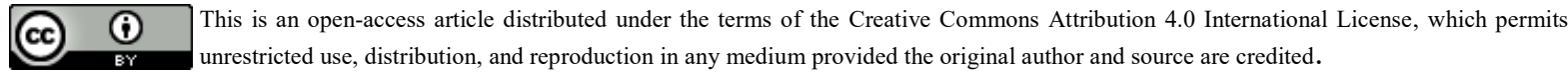

\section{Introduction}

Identifying dead persons is a challenge for police and forensic experts. Multiple reasons are attributed for not being able to identify such dead bodies - no proper history, absence of an identity card, severe decomposition, acute facial injuries due to blunt force trauma like road traffic injuries or rail track injuries, postmortem injuries, and the absence of antemortem data to be compared are some possible causes.[1]The Police should first declare that 
identifying the decedent is impossible through their investigations before commencing the death investigation. Discussing the identification parameters, the four primary and most important parameters are fingerprints, dental data, radiology/X-rays and DNA. Except for the fingerprints, other methods are not widely or routinely used in Sri Lanka because of the high cost and unavailability of the antemortem data for comparison.

The identification process is usually time-consuming due to many reasons. The resulting significant hardship is the constant delay in performing postmortem examinations. According to this study findings, there had been instances where the dead body had to be kept in the mortuary coolers for around one year solely because the police officer had not visited to initiate the postmortem examination. Hence, those corpses continuously occupy the limited number of coolers. With increasing postmortem interval, post-mortem changes will set in, which also create more hardships. At times, the body had been mummified or putrefied, thereby posing a challenge in interpreting external and internal injuries. When the refrigerators are out of order, and if by any chance it gets delayed in repairing, the dead bodies inside tend to putrefy causing many problems to the hospital and its surroundings with unbearable odours.

The present retrospective data analysis evaluated the mean time period in days taken to dispose of a dead body. The demographic profile of the decedents is also analyzed. Another objective of this study is to revisit and highlight the hardly spoken laws and related procedural circumstances in the disposal of unknown decedents.

\section{Methodology}

A retrospective data analysis was performed using the registers maintained by the hospital at the Judicial Medical Officer's (JMO's) Office and overseer's office. The communication file with the police, the file maintained for the hospital coolers were also perused. The data were analysed through the SPSS 21 package. All the post-mortems registered as unidentified dead bodies (141 dead bodies from August 2016 to August 2020) were included. Dead bodies of those initially presented as unidentified, but later claimed and identified, were excluded. The ethical clearance was obtained from the Ethical Review Committee of Colombo South Teaching Hospital. Disposal of an unidentified dead body can only become a success if all the stakeholders such as police, Inquire into Sudden Deaths, magistrates, hospital staff members including the workers at a JMO office and florists are committed alike. Since there was no written document pertaining to the procedure of disposal of an unidentified dead body, the author utilized the working experience gathered from above stakeholders while providing her service. In addition to that the law pertaining to the inquest procedure is also explored.

\section{Results}

The number of post-mortem examinations carried out from the category of unidentified dead bodies from August 2016 to August 2020 was 141, and the total number of dead bodies investigated was 4472 .

\section{Sex}

The study population comprised of $92 \%$ males $(n=130)$ and remaining $08 \%$ females $(n=11)$. The male to female ratio was almost 13: 1 in this study

The age ranges and the number of deaths in each category

The majority $(\mathrm{n}=81,57 \%)$ of the 141 decedents belonged to the age group of $61-80$ years and the distribution of age is shown in Table 01 .

Table 01: The distribution of age

\begin{tabular}{lr}
\hline Age Category & $\begin{array}{r}\mathbf{N}=\mathbf{1 4 1} \\
\mathbf{n}(\boldsymbol{\%})\end{array}$ \\
\hline$>80$ & $12(09)$ \\
$61-80$ & $81(57)$ \\
$41-60$ & $38(27)$ \\
$21-40$ & $08(06)$ \\
$<20$ & $02(01)$ \\
\hline
\end{tabular}

\section{The place of death}

Sixty-seven (48\%) subjects of the sample had died after admitting to a hospital ward while the rest were handed over as dead bodies ( $\mathrm{n}=74,52 \%)$.

\section{Number of days treated in a ward}

The maximum number of days that a patient was admitted before death, was 19 days. The number of mean days that a patient was treated in the hospital was 2.35 days ( $\mathrm{SD} \pm 3.606)$. The median number of days stayed at the hospital is 0.0 . (The Interquartile range was $(\mathrm{Q} 3-\mathrm{Q} 1)$ is $4-0=4)$.

\section{By whom the patients/decedents had been handed over to the hospital}

The Police had handed over the majority of unidentified dead bodies (both the patients and the decedents $),(\mathrm{n}=71,51 \%)$. The second category reported $(\mathrm{n}=58,41 \%)$ was admitted or handed over to the hospital by other means such as selfadmissions, passers-by, or by untraceable persons 
(who had given false details). The toll-free ambulance service (1990) has admitted/submitted 11 individuals $(08 \%)$.

The time taken to perform the post-mortem examination from handing over and the time taken to dispose of the dead body upon postmortem

The average (mean represented in days) period to complete the autopsy from handover was 90 days ( $\mathrm{SD} \pm 58.920)$, and to dispose of the dead bodies with completed post-mortem examinations had only taken $5(\mathrm{SD} \pm 2.525)$ days.

\section{The categories of deaths presented}

Analysing the type of the incident revealed that a significant percentage had died from natural diseases, comprising $81 \%(n=114)$. Two cases had been identified, where one had died due to selfsuspension and the other person had been stabbed to death. The type of incident the caused for the demise is shown in Table 02 .

Table 02: The type of the incident that caused the death

\begin{tabular}{lr}
\hline Category & $\begin{array}{r}\mathbf{N}=\mathbf{1 4 1} \\
\mathbf{n}(\boldsymbol{\%})\end{array}$ \\
\hline Natural disease & $114(81)$ \\
Rail tract injuries & $12(09)$ \\
Road traffic trauma & $06(04)$ \\
Suicides and homicides & $02(01)$ \\
Not known & $07(05)$ \\
\hline
\end{tabular}

\section{Discussion}

The discussion is based on three aspects. The first is to study the demographic profile of the unidentified decedents. The second is to calculate the average delay of the dead body disposal from the point of handing over to the hospital and surrounding hardships faced by the hospital, and finally to study the legal provisions undertaken in Sri Lanka for the disposal of unidentified dead bodies.

According to the present study, the total number of post-mortems belonging to unidentified decedents were $\mathrm{N}=141$ during the four years, comprising 3\% of the total number of post-mortem performed (4472). The prevalence of unidentified dead bodies presented to different centres of India indicated as 4\%[1],10.30\%[3] and 7.54\%.[4] Also, a study had shown a very high number of unknown decedents in India, raising the figure up to $24.5 \%$ at the time of death, but later on it had become $12.70 \%$ since relatives had managed to identify subsequently. The male to female ratio was almost 13: 1 in this study ( $\mathrm{n}=130: 11$, respectively). The age group with most of the deaths was 61-80 years, $n=81(58 \%)$. Similar to studies in other countries, the number of deaths below the age of 40 years was very low in this study.[2,3]A contrasting finding had illustrated in Thane, Maharashtra in India, where the majority of unknown dead bodies were from the age range of 31 40 years.[6]

Sixty-seven ( $48 \%$ ) of unidentified individuals in this study presented to the hospital as patients initially had passed away while being treated. That number was almost equal to $50 \%$ of all the unidentified dead bodies investigated in this study. The author wishes to share the personal experience gathered throughout the carrier in this context. The guardians or the relatives had provided false details to the hospital at the time of admission. Simultaneously, when the patients were in critical condition, the guardians or the relatives want to evade the burden of looking after the patients by admitting critically ill patients. Upon death, a guardian could not be traced by the hospital authorities as they had provided false details. For a certain percentage, the hospital records that perused had indicated that the deceased was a beggar or a road dweller resulting in no claimant of the dead person.

Analysing the party who admitted/submitted the decedent revealed that the Police had handed over seventy-one decedents $(50 \%)$ to the hospital (it includes both the patients and the decedents). The involvement of the police is generally necessitated when a person does not have any relative or any responsible person to look after them. This enables the staff members of the hospital to arrive at an indirect assumption that most decedents within this category may be street-beggars or psychotic patients who had lost contact with their families. An 8\% $(n=11)$ of all admissions had been handed over by the 1990 ambulance service, a free-of-charge service.

The hospital concerned has only 36 coolers. If many unknown dead bodies are to be accommodated in this limited number of coolers, only a few refrigerators are available for the rest of the dead bodies that need to be routinely handled. The average time taken (in days) to perform the post-mortem examination from the hand-over time was 90 days; on average, approximately three months. In a study done in Bangalore, the average time interval between the recovery of a body and performing the autopsy was about 10-13 days.[2] India, the maximum number of days taken was 73 days.[3] A study performed in Sri Lanka revealed that it had taken 52 days and 21 days respectively in the Western 
province and in peripheral units to conduct the postmortem examination. [7]

The primary objective of this data analysis was to obtain evidence about the average (mean rather) delay (in days) of the post-mortem examination and also the time taken for disposal. Therefore, with this study it was evidentially shown that there had been a significant delay from the undertaking of the body to the mortuary and to the time of performing the autopsy. As per the existing practices and laws of the country, the police are informed to take measures if a dead body has not already been claimed by relatives. Upon confirmation as an unidentified decedent, a police officer should be present in order to commence the death investigation according to the inquest law. The police officers are routinely informed to be present at the JMO's office as soon as they are informed, but it is not much complied according to the author's experience and also according to the communication file of the hospital concerned.

Occasionally, refrigerators are out of order as per the hospital records. In such a situation, the putrefaction of already accommodated bodies causing much smell and an unpleasant environment triggers huge problems, not only within the hospital premises but also in its vicinity. Nevertheless, with repeated requests, finally, the post-mortem is done, and the disposal of the dead body happens regularly. The time for this was 4.9 days on average (mean) to register the death of the unknown person. According to a study done in Sri Lanka, it had taken 79 days in selected tertiary care units and 25 days in some selected peripheral areas of the country to bury a dead body. [7]

In the present study, most deaths were due to natural diseases, $\mathrm{n}=114(81 \%)$, followed by rail track injuries, $n=12(9 \%)$. The number of deaths due to road trauma was $06,(4 \%)$, and seven deaths were classified as unascertained (5\%). According to a study in India, it was unable to provide a "definite opinion as to the cause of death in $28 \%$ of the cases". [8] There had been two deaths, categorized as "others" in this study, and it was consistent with one case being a suicidal hanging and the other was a case of homicide. Every similar study done elsewhere had shown a preponderance of natural deaths.[5]

Not all the unidentified dead bodies were handed over after death. Sixty-seven (48\%) subjects of the sample had died only after admitting to a hospital ward. According to this study, the number of mean days that a patient was treated in the hospital was 2.35 days $(\mathrm{SD} \pm 3.606)$.

The Department of Police has a significant role in managing the unidentified dead bodies. An inquest cannot be commenced until a decedent is declared as an unidentified person. Once it is confirmed, a letter from the Officer-in-Charge of the area should be provided either to the Magistrate or to the ISD (Inquirer into Sudden Deaths) signifying that identification of the deceased is currently impossible according to the procedural rules (Departmental Orders) of Sri Lanka Police[9], and then proceed with the disposal of the dead body after the death investigation.

A postmortem examination cannot be performed unless the police investigations are completed to indicate a decedent is an unidentifiable person. If the police officer comes with the proper order there is no delay from the hospital service since the postmortem is performed on the day itself or at least the day after. It is obvious that the delay is with the police department. With this study, it is evidentially shown that the significant delay occurs through the Police, creating severe hardships to the health sector.

According to the practice, at least it will take two weeks for police to investigate the case. Once an unidentified dead body is present, the relevant police station is informed to gather information about the decedent. The fingerprints are obtained and sent to the Registrar of Fingerprints to be compared with already available fingerprints at the Criminal Records Division of Sri Lanka. The Police take photographs and upload them into the Virtual Private Network (VPN) of the Sri Lanka Police to be shared with all the police stations. If a person complains about a missing person, the police stations islandwide accesses the VPN, and provide information to trace any missing person.[10] So it is essential to provide a significant period of time to the Department of police to complete their investigation. But if this delay extends unnecessarily the underlying reasons are to be investigated which is beyond the parameters of this study.

But if this time period is extending unduly as illustrated in this study, there is a point to be considered. As judicial medical officers we also can provide assistance to identify the dead people. The author suggests uploading at least the sex, age, the place of discovery and the attire pertaining to the unidentified decedent in the official web page of the hospital as a separate menu, which will help the public to identify the decedents quickly. It will help the Department of Police as well to get shorten the 
investigation time that would take to confirm it as an unidentified decedent.

In Sri Lanka, an unidentified decedent is not disposed of without an inquest although the legal proceedings related to inquest do not explicitly mention about unknown decedents. The inquest procedure is defined in the Code of Criminal Procedure Act (No. 15 of 1979) in Sri Lanka from Sections 369 to 373.[11] However, none of the sections highlighted a special procedure to be followed regarding unidentified dead bodies. Instead, there is a "working guideline/departmental orders adopted by the responsible stakeholders such as Police, ISD, Judiciary and Forensic Pathologists, hospital directors, the Registrar of birth, marriage and death of the area, and by florists" (personal communications on September 2020, the Consultant Judicial Medical Officer of the hospital concerned). Nevertheless, the existing procedure covers almost all the necessary steps to be followed when an unknown dead body is encountered within the facilities available in the country. Since there is no stipulated law that to be followed concerning an unidentified dead body, the author attempted to find any reference to discover the origin of the definition of "Inquest procedure" as per the Code of Criminal Procedure Code, Sri Lanka. However, no proper answer surfaced from international textbooks of forensic medicine. [12-14] The definition used for generations is "An inquest is a judicial inquiry in common law jurisdictions, particularly to determine the cause of death". This does not cover the part of the decedent identification.[15]

A broader definition of the inquest used in Sri Lankan academics also reads as "a public and judicial inquiry held to determine the facts related to incidents/deaths such as the cause of death and manner of death and to identify the deceased in case of unknown". Anyhow, the author believes that though there is no stipulated law as to how to investigate unidentified decedents, the procedure followed is entirely satisfactory at present. However, the emphasizing fact is, it triggers numerous limitations once applied in the real world, especially with the part or role played by the Police.

The burial is the only option, and cremation is not allowed for unidentified dead bodies. The burial should be done in a "marked place" to be exhumed, if needed, for further investigations. The above study and the details indicate that the Police in Sri Lanka have a significant role in the timely disposal of unidentified dead bodies. Having a specified legal procedure rather than having "working guidelines" will help to lessen the unwanted delays that occur during the procedure of disposal of unidentified decedents.

\section{Conclusion and recommendations}

The findings surfaced from the present four-year retrospective data analysis are mostly comparable to many epidemiological factors presented by similar studies. Most of the decedents were of the male sex and within the age range of 61-70 years and had died due to natural diseases. The delay of initiating death investigation procedures is alarmingly high, causing many difficulties for the hospital. Creating a menu item or a submenu item in the official web page of the hospital with the currently available information of unknown decedents is recommended, which would be highly beneficial for the public. The Code of Criminal Procedure does not directly recognise the death investigations of unidentified dead bodies. However, the disposal process would have been much efficient without creating problems for the health sector if the inquest procedure especially identifies the unidentified dead bodies.

\section{Acknowledgments}

Mr. Sithum Manjika (Statistical Officer, Department of Community Medicine, University of Sri Jayewardenepura), Dr. P. Dasanayaka and Dr. SR Hulathduwa (Consultant Forensic Pathologists), Dr. ELPA Jayathilaka, Dr. PH Jayawardana, Dr. RMTS Weerasingha, Dr. P.A.C.T. Kumarasiri, former demonstrators attached to the Department of Forensic Medicine, University of Sri Jayewardenepura, Sri Lanka are gratefully acknowledged for the guidance, statistical analysis and the assistance provided during the data collection.

\section{Disclosure statement}

Conflicts of interests: The author declares that she has no conflicts of interest.

Funding: None

\section{References}

1. Kumar A, Dasari H, Singh A. Cause of Death in "John Doe \& Jane Doe": A 5 year review. Journal of Clinical and Diagnostic Research. 2014;8(8):01-04. doi: 10.7860/JCDR/2014/ 8876.4661 .

2. Kumar TN, Jagannatha SR, Venkatesha VT. Demographic Profile of Unknown Dead Bodies in South Bangalore. Indian Journal of Forensic Medicine \& Toxicology. 2018;12(2): 769.DOI:10.5958/0973-9130.2018.00077.4

3. Patel DP, S, Alpesh CV, Shaikh MM, Pankaj P, Kalpesh S. Profile of unidentified dead bodies brought to mortuary, Civil hospital, Ahmedabad. Journal of Forensic Medicine and Toxicology. 
2016;33(2):98-102 [cited2020 Sep 4]. Available from: http://www.indianjournals.com/ijor.aspx? target $=$ ijor:jfmt $\&$ volume $=33 \&$

issue $=2 \&$ article $=004$. Online ISSN : 0974-4568.

4. Chattopadhyay S, Shee B, Sukul B. Unidentified bodies in autopsy-A disaster in disguise. Egyptian Journal of Forensic Sciences. 2013 Dec 1;3(4): 112-5 https://doi.org/10.1016/j.ejfs. 2013. 05.003

5. Prasad M, Shandil A, Choudhar R. Pattern of Death of Unidentified Cases: A mortuary based study from Patna Medical College, Bihar. Journal of Medical Science And clinical Research. 2019;7(1):1004-1007. DOI: https://dx.doi.org/ $10.18535 / \mathrm{jmscr} / \mathrm{v} 7 \mathrm{i} 1.175$.

6. Sakthimani M, Peranantham S. Autopsy based analysis of unidentified dead bodies in a tertiary care hospital of South India. Journal of Indian Academy of Forensic Medicine. 2019;41(1): 303 DOI: 10.5958/0974-0848.2019.00007.1

7. Sri Lanka Police: The Departmental Order Book. C 9. Identification of unknown dead bodies: fingerprints and obtaining photographs.

8. Darshana S. VPN system to interlink Police service. Daily Mirror Sri Lanka.PressReader.com. [cited 2020 Sep 21]. Available from: https://www.pressreader.com/ sri-lanka/daily-mirror-sri-lanka/20140903/ 281522224273839 [Accessed 09th October 2020]

9. Inquest. In: Wikipedia2020 [cited 2020 Sep 21]. Available from: https://en.wikipedia.org/w/ index.

10.php?title $=$ Inquest\&oldid $=943288432$ [Accessed 09th October 2020]

11. Code of criminal procedure act, no. 15 of 1979. Sri Lanka: Department of Government Printing; 1979.Code Of Criminal Procedure Act (No. 15 of 1979).

12. Saukko P, Knight B. Knight's Forensic Pathology Fourth Edition. 4th ed. Boca Raton: Chapman and Hall/CRC; 2015.

13.Spitz W, Diaz F, Fisher R. Spitz and Fisher's medicolegal investigation of death. 4th ed. USA: Charles C Thomas; 2006.

14. Dominick DiMaio, Vincent J.M. DiMaio, M.D. Forensic Pathology.[ Boca Raton] CRC Press;2002.

15. Inquest. In: Wikipedia 2020 [cited 2020 Sep 21]. Available from: https://en.wikipedia.org/w /index.php?title=Inquest\&oldid=943288432 [Accessed 09th October 2020] 